\title{
Potential for between-mudflat movement and metapopulation dynamics in an intertidal burrowing amphipod
}

\author{
David Drolet ${ }^{1, *}$, Trevor T. Bringloe ${ }^{2}$, Michael R. S. Coffin ${ }^{2}$, Myriam A. Barbeau ${ }^{2}$, \\ Diana J. Hamilton ${ }^{1}$ \\ ${ }^{1}$ Biology Department, Mount Allison University, Sackville, New Brunswick E4L 1G7, Canada \\ ${ }^{2}$ Department of Biology, University of New Brunswick, Fredericton, New Brunswick E3B 5A3, Canada
}

\begin{abstract}
We evaluated the potential for between-mudflat dispersal of individuals of the burrow-dwelling amphipod Corophium volutator. We first estimated the distances travelled by measuring vertical distribution of swimmers in the water column and their activity in relation to the tidal cycle. We found amphipods were located high over the substratum (up to $4 \mathrm{~m}$ ) with little vertical structure, and swimming occurred during periods of maximum water velocity (large peak during flood tide). Based on the behaviour of amphipods and information on hydrodynamics, we estimated that an individual could move between 0.4 and $14.4 \mathrm{~km}$ toward the upper part of the bay in a single swimming event. This distance is sufficient to allow travel from one mudflat to the next in only a few swimming steps. To identify potential migration routes, we also sampled along a shore (covered in a narrow band of mud) between 2 major mudflats. Patterns in density suggested there was a presence of a travelling wave of individuals, which is consistent with predictions made from their swimming behaviour. We evaluated the possibility that $C$. volutator in the upper Bay of Fundy are found in one or several metapopulations, where the large and discrete mudflats are connected by the dispersal of individuals. We propose a refined, spatially structured population model (modified from terrestrial metapopulation models) applicable to soft sediment environments in marine intertidal zones, in which several groups of a few intertidal flats are connected by the unidirectional movement of the amphipods. The dynamics will largely be determined by the detailed spatial arrangement of intertidal flats and corridors, as well as by the details of the hydrodynamic conditions and behaviour of organisms.
\end{abstract}

KEY WORDS: Marine metapopulation · Soft sediment - Dispersal · Corridor · Corophium volutator Selective tidal-stream transport

\section{INTRODUCTION}

Movement of organisms to and from a population can have important effects on local population dynamics (Hanski 2001). Identifying networks of spatially discrete populations that exchange individuals is important when establishing conservation strategies, as some populations may act as sources of indi- viduals without which other populations (sinks) could not be viable (Pulliam 1988). Connectivity of these populations also influences probability of local extinction and probability of recolonization after extinction (Hanski 1998). The theory behind the dynamics of such metapopulations in highly fragmented terrestrial habitats is well developed (e.g. Hanski \& Ovaskainen 2003). It is clear that marine populations 
are patchily distributed and exchange individuals, especially through planktonic larval stages. Consequently, such populations are increasingly viewed as metapopulations in the marine ecological literature, although it may not be the most appropriate approach in many cases (Grimm et al. 2003). Marine metapopulations that resemble their terrestrial counterparts (a large number of discrete populations undergoing colonization or extinction dynamics) appear to be rare; examples include copepods in rocky intertidal pools (Dybdahl 1994) and, potentially, giant kelps in shallow coastal waters (Reed et al. 2006). A set of conditions (reviewed in the Discussion) is required for metapopulation models to be more informative than other population models, and these should be assessed before adopting a metapopulation approach (Hanski 1997, Grimm et al. 2003). In systems where a metapopulation approach can be appropriate and informative, marine ecologists will need to incorporate structural differences of the marine environment into the existing body of theory (e.g. spatial arrangement of suitable habitat, means of dispersal of organisms; Kritzer \& Sale 2006) before applying these models.

In marine coastal environments, sediment accumulates in zones of relatively low energy, creating spatially well-defined intertidal sandflats or mudflats. The intertidal flats often support very dense populations of infaunal and epifaunal invertebrates (e.g. Armonies \& Hartke 1995, Junkins et al. 2006), and, in the past, different flats were generally studied as independent populations or communities (e.g. Peer et al. 1986, Pridmore et al. 1990, Barbeau et al. 2009). Dispersal of postsettlement stages and of different stages for species with direct development plays an important role in intertidal flat population dynamics. Some species move passively with resuspended sediment (Emerson \& Grant 1991, Jennings \& Hunt 2009), whereas others drift in the water column (Cummings et al. 1995). Movement allows for the recolonization of disturbed areas (Thrush et al. 1991), can drive migration (Armonies 1996) and can lead to the formation of spatial patterns (Drolet \& Barbeau 2011). Long-distance dispersal of infauna is assumed to be possible, but has never been measured directly.

The upper Bay of Fundy, on the Atlantic coast of Canada, has the highest tidal amplitude in the world (up to $16 \mathrm{~m}$, Desplanque \& Mossman 2004). Several massive intertidal sandflats or muflats are present in the upper sections of the bay (Fig. 1). On the mudflats, the burrow-dwelling amphipod Corophium volutator is often the dominant infaunal invertebrate

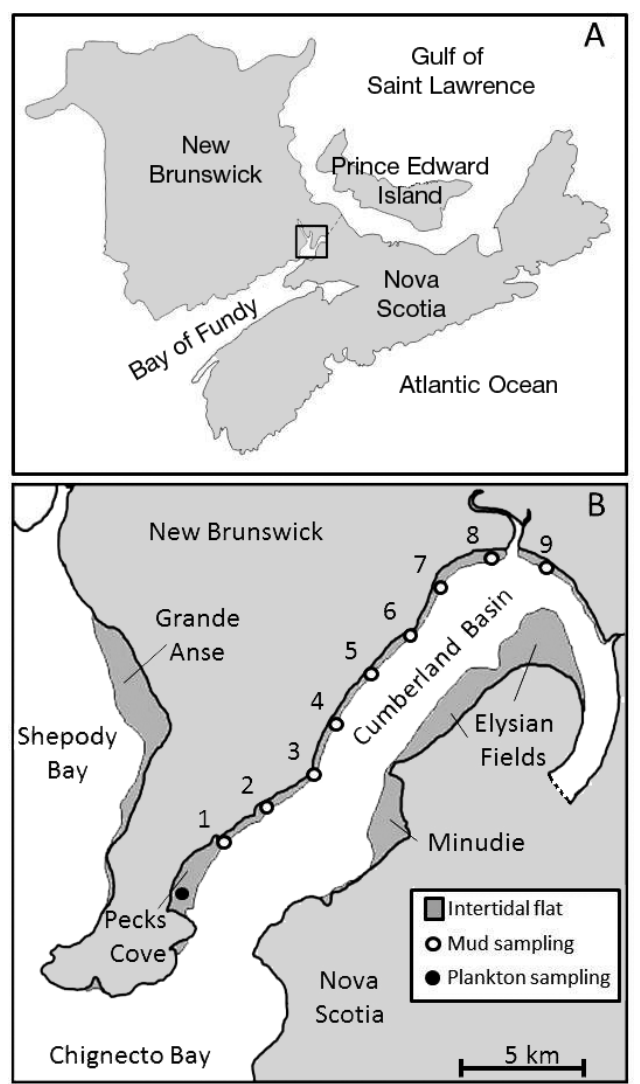

Fig. 1. (A) The Maritime Provinces of Canada. The square marks the general study area. (B) Cumberland Basin, showing the major intertidal flats and the extent of the muddy shores. Symbols and numbers denote the approximate location of the different sampling stations

with densities peaking at $\sim 60000$ individuals (ind.) $\mathrm{m}^{-2}$ (Peer et al. 1986). This amphipod is of primary importance for the mudflat ecosystems owing to its effects on mud stability through the construction of burrows (Mouritsen et al. 1998) and its role as a major food source for different species of fish (both bottom and pelagic feeders; Gilmurray \& Daborn 1981, McCurdy et al. 2005) and for hundreds of thousands of migratory shorebirds (Hicklin \& Smith 1984). Population dynamics vary substantially among mudflats (Barbeau et al. 2009) but vary little within a mudflat (Drolet \& Barbeau in press). Studies of population densities of $C$. volutator over a relatively long time span collectively show that some mudflats are stable with yearly high densities, whereas important interannual variation and population crashes are observed at other sites (for the Bay of Fundy, Hicklin \& Smith 1984, Peer et al. 1986, Shepherd et al. 1995, Sprague et al. 2008, Barbeau et al. 2009, Coulthard \& Hamilton 2011, MacDonald et al. 2012; crashes were 
also observed in Europe, Jensen \& Mouritsen 1992). Outside the large mudflats, the shores of the upper Bay of Fundy are often covered with mud in much narrower and steeper bands (50 to $200 \mathrm{~m}$ wide, hereafter referred to as muddy shores). To our knowledge, this habitat has never been studied but shows conditions potentially favourable for survival of C. volutator. Presence of these muddy shores could act as corridors (Haddad et al. 2003) that could enhance the movement of infauna between patches (i.e. mudflats).

Corophium volutator individuals actively emerge from their burrows during periods of immersion and drift with tidal currents in the water column. On both sides of the Atlantic Ocean, large numbers of $C$. volutator swim in the summer, particularly during periods of immersion occurring around the new and full moons at night (Hughes 1988, Drolet \& Barbeau 2009). In Europe, C. volutator was reported to swim both at ebb tide (Hughes 1988) and flood tide (Essink et al. 1989), but this aspect was never investigated in North America. At Pecks Cove in the upper Bay of Fundy, individuals are found in the water column everywhere across the mudflat (Drolet 2009), and their direction of transport is determined by prevailing tidal currents (Drolet \& Barbeau 2011). Swimming effectively mixes individuals and homogenizes population dynamics within a mudflat (Drolet \& Barbeau in press). Additionally, this movement creates spatial patterns in density; some zones receive larger numbers of immigrants (through swimming), which translates into zones with higher densities at scales of 10 s to 100 s of metres (Drolet \& Barbeau 2011).

In this study, we assessed the possibility that mudflats in the upper Bay of Fundy constituted one or several metapopulations of Corophium volutator and evaluated the general framework that best described the dynamics of the system. Important information about within-mudflat population structure, variation in population dynamics among mudflats and longterm trends in density is already available and is reviewed in the 'Discussion'. However, little is known about large-scale movement of the species, and here we assess the possibility of between-mudflat dispersal. The general hypothesis is that amphipods leave some mudflats through swimming and use the muddy shores as corridors during a step migration that eventually leads them to another mudflat. We first assessed the potential for long-distance swimming by monitoring the swimming of $C$. volutator at different heights (up to $4 \mathrm{~m}$ ) within the water column above the substratum, with the premise that amphipods caught high in the water column are more likely to move longer distances than individuals swimming closer to the substratum. Second, we measured the timing of swimming in relation to a tidal cycle to determine (1) whether individuals swim during periods of high water velocity and (2) the extent and direction of resulting movement. Flood-tide swimming would result in movement toward the upper parts of the bay, slack-tide swimming in no net transport and ebb-tide swimming in movement toward the lower parts of the bay. Third, we followed population trends of $C$. volutator at many locations on the muddy shore (located between 2 major mudflats) to verify amphipod presence and to detect potential migration routes.

\section{MATERIALS AND METHODS}

\section{Study area}

We concentrated our work in the Cumberland Basin, the eastern branch of Chignecto Bay, which is in turn the northwestern branch of the Bay of Fundy (Fig. 1). The semidiurnal tides in this area range in amplitude from $\sim 7$ to $14 \mathrm{~m}$ (Canadian Hydrographic Service data). There are 3 major mudflats in Cumberland Basin: (1) Pecks Cove, which is located in a $3.5 \mathrm{~km}$ wide bay on the southwestern shore and has an intertidal zone that extends about $850 \mathrm{~m}$ from shore, (2) Elysian Fields, which extends for $\sim 10 \mathrm{~km}$ along the current-sheltered northeastern shore, and (3) Minudie, which is located in a $4 \mathrm{~km}$ wide bay on the southeastern shore and has an intertidal zone extending $\sim 1.5 \mathrm{~km}$. The sediment in Pecks Cove and Minudie consists of mostly fine mud (average particle size, $\sim 25 \mu \mathrm{m}$ ) and has an unconsolidated top layer of oxygenated mud that ranges from 3 to $8 \mathrm{~cm}$ in depth (T. Gerwing unpubl.). The Elysian Fields are composed of a mix of sand (far north) and mud (south); the muddy sections have a shallow top layer $(\sim 1 \mathrm{~cm})$ of unconsolidated mud. The majority of the western shore of Cumberland basin is covered by narrow muddy shores (50 to $200 \mathrm{~m}$ long intertidal zone, Fig. 1) that have fine sediments similar to Pecks Cove and Minudie. A few rocky outcrops and rivers break this otherwise continuous corridor of mud. The current patterns are mostly tidally driven, and water velocity can reach $\sim 2 \mathrm{~m} \mathrm{~s}^{-1}$ at some locations during periods of peak water motion (Dupont et al. 2005; Fig. 2). During flood tide, the current generally flows northeast, and the opposite is observed at ebb tide (Fig. 2). 


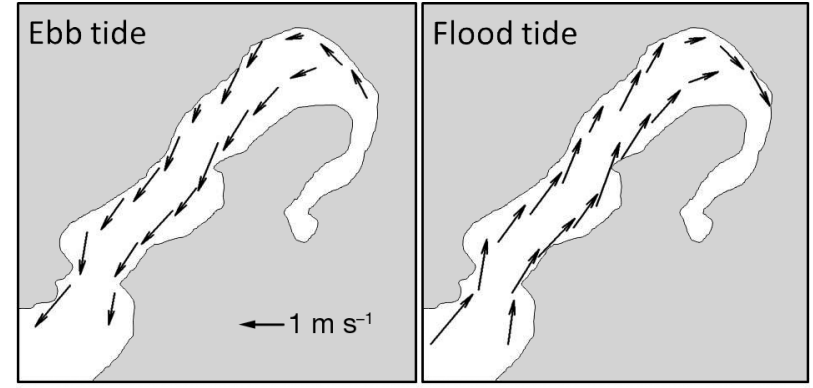

Fig. 2. Vector field showing direction and velocity of tidedriven currents at ebb and flood tide along the shores of Cumberland Basin. Data were generated by the WebTide tidal prediction model (Dupont et al. 2005) for the periods of peak water velocity for a tidal amplitude of $\sim 10.5 \mathrm{~m}$

\section{Vertical distribution of swimmers in the water column}

To determine how high above the substratum Corophium volutator individuals swim and hence to infer the potential they have for long-distance movement, we measured the abundance of swimming individuals at different heights over the Pecks Cove mudflat (Fig. 1). We set plankton nets $(80 \mathrm{~cm}$ long, $20 \mathrm{~cm}$ diameter opening, $180 \mu \mathrm{m}$ mesh; Drolet \& Barbeau 2009) along $4 \mathrm{~m}$ high towers at $0.3,1,2,3$ and $4 \mathrm{~m}$ above the mudflat surface (Fig. 3 ). Visits to these towers resulted in some disturbance to the sediment (seen in Fig. 3); however, we were confident that this disturbance did not affect results, because the area disturbed was relatively small, and our presence affected only a small portion of organisms that could potentially swim and enter the nets. Further, trials in other areas have suggested there were no effects of workers' disturbance on C. volutator density in surrounding sediment (D. J. Hamilton unpubl. data, cited in Hamilton et al. 2006). The nets at 0.3 and $4 \mathrm{~m}$ were immersed for $354 \pm 2$ and $162 \pm 18 \mathrm{~min}$, respectively (mean $\pm \mathrm{SE}$, based on 3 visual measurements for tidal amplitudes of 10.7, 11.5 and $13.5 \mathrm{~m}$ ). The nets were free to rotate, and observations showed they aligned well with the current direction. We set a group of 3 towers arranged parallel to shore $(10 \mathrm{~m}$ distance between each tower) at $400 \mathrm{~m}$ from shore. Sampling was conducted over 3 individual night tides during 3 sampling periods in summer 2010 ( 25 to 28 June, 10 to 13 July and 8 to 11 August) centred on a new or full moon. These periods correspond to peak times in swimming activity on this mudflat (Drolet \& Barbeau 2009). To estimate the volume of water passing through the plankton nets, we attached a plaster hemisphere (Komatsu \& Kawai 1992) near the mouth

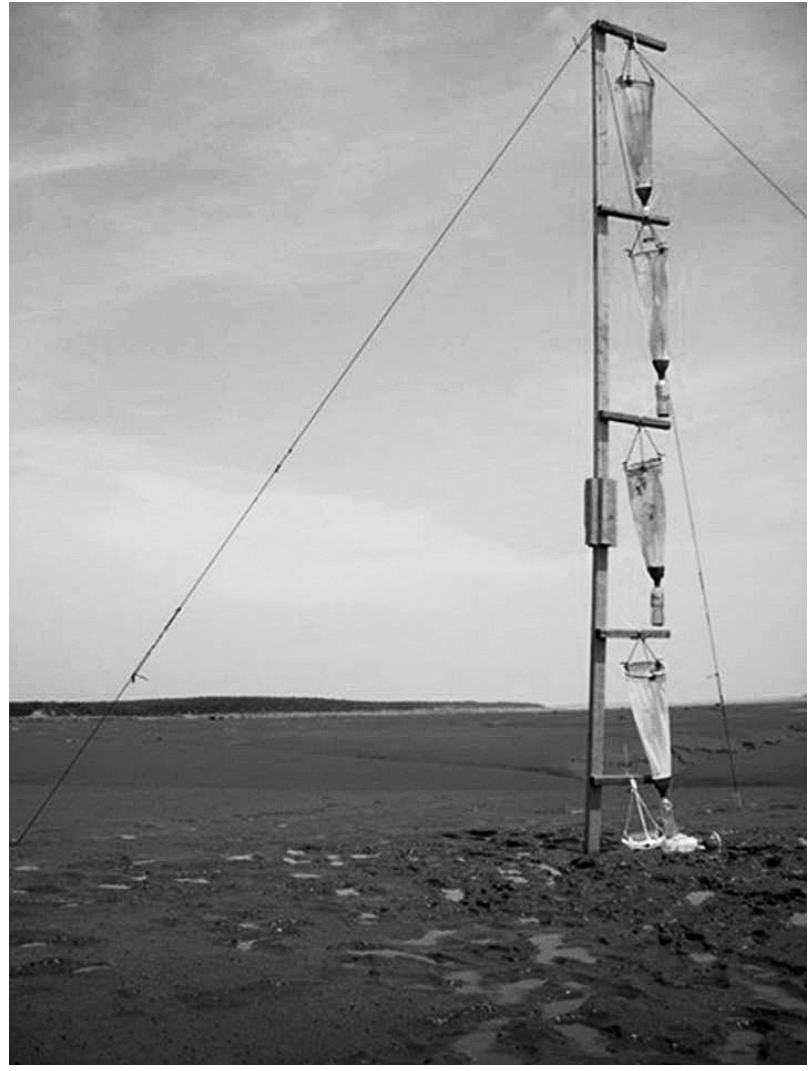

Fig. 3. Tower used to sample the vertical distribution of swimming Corophium volutator in the water column on the Pecks Cove mudflat during summer 2010. Plankton nets (20 cm diameter opening) are located $0.3,1,2,3$ and $4 \mathrm{~m}$ above the mudflat substratum

of each net. The mass loss of plaster was converted into a linear amount of water passing a point (the plaster hemisphere) by using a calibration performed at a known water velocity in a saltwater flume. The linear amount of water was then multiplied by the area of the net opening to obtain a volume of water filtered by the net (calibration equation: volume $\left[\mathrm{m}^{3}\right]$ $=37.3 \times$ mass loss of plaster $[\mathrm{g}]+9.7, \mathrm{n}=16, \mathrm{r}^{2}=0.59$, $\mathrm{p}<0.001$; Bringloe 2011). The matter collected by the plankton nets was preserved in $95 \%$ ethanol and was later sorted under a dissecting microscope. Samples containing a large amount of material were split with a Folsom plankton splitter (Wildco ${ }^{\circledR}$, portion of initial sample sorted ranged from 1:2 to 1:512) until a manageable number of amphipods was obtained (between 100 and 200). C. volutator individuals were counted, and the number caught by each net was converted into a density (ind. $\mathrm{m}^{-3}$ of water) by dividing by the water volume estimates.

The spatial and temporal trends in density of swimming Corophium volutator were evaluated with a 
mixed-model split-plot ANOVA. The model included the random factors Round (3 sampling rounds: June, July and August), Night (3 sampling nights nested within Month) and Tower (3 replicate towers), and the fixed factor Height $(0.3,1,2,3$ and $4 \mathrm{~m}$ above the substratum). Appropriate denominators for F-ratios (Table 1) were determined as described in Underwood (1997) and Quinn \& Keough (2002). Densities of swimming $C$. volutator were log transformed to meet assumptions of homogeneity of variance and normality of residuals.

\section{Timing of swimming within a tidal cycle}

To gain insight on the hydrodynamic conditions at times when individuals swim and the general direction towards which currents transport Corophium volutator, we evaluated variation in density of swimming individuals within a period of immersion. This was done for 3 tides on the overnights of 24-25 July, and 21-22 and 22-23 August 2010. We worked from an anchored boat at a distance of $\sim 150 \mathrm{~m}$ from shore on the Pecks Cove mudflat. We did tows with a plankton net $(45 \mathrm{~cm}$ diameter opening and $180 \mu \mathrm{m}$ mesh size) at 30 min intervals starting 20 min after the area under the boat was immersed. A tow consisted of tossing the net (attached to a rope) in the water, letting the net sink to the bottom (a small float was attached to the ring of the net to prevent dragging in the substratum) and bringing the net back to the boat by slowly pulling the rope. The strength of the tidal currents resulted in oblique tows that lasted $56 \pm 5(\mathrm{SE}) \mathrm{s}$. The amount of water passing through the plankton net was estimated with a mechanical

Table 1. Structure of the mixed-model split-plot ANOVA used to analyze the vertical distribution of swimming Corophium volutator over the Pecks Cove mudflat, Bay of Fundy, during summer 2010. All sources of variation are random factors, except for Height which is a fixed factor

\begin{tabular}{|c|c|}
\hline Source of variation & $F$ or quasi $F$-ratio \\
\hline Round $R_{i}$ & $\left(\mathrm{MS}_{R}+\mathrm{MS}_{N(R) T}\right) /\left(\mathrm{MS}_{R T}+\mathrm{MS}_{N(R)}\right)$ \\
\hline Night(Round) $N(R)_{j(i)}$ & $\mathrm{MS}_{N(R)} / \mathrm{MS}_{N(R) T}$ \\
\hline Tower $T_{k}$ & $\mathrm{MS}_{T} / \mathrm{MS}_{R T}$ \\
\hline Round $\times$ Tower $R T_{i k}$ & $\mathrm{MS}_{R T} / \mathrm{MS}_{N(R) T}$ \\
\hline Night(Round) $\times$ Tower $N(R) T_{j(i) k}$ & No test. Between-subject error \\
\hline Height $H_{l}$ & $\left(\mathrm{MS}_{H}+\mathrm{MS}_{R T H}\right) /\left(\mathrm{MS}_{T H}+\mathrm{MS}_{R H}\right)$ \\
\hline Round $\times$ Height $R H_{i l}$ & $\left(\mathrm{MS}_{R H}+\mathrm{MS}_{N(R) T H}\right) /\left(\mathrm{MS}_{R T H}+\mathrm{MS}_{N(R) H}\right)$ \\
\hline Night(Round) $\times$ Height $N(R) H_{j(i) l}$ & $\mathrm{MS}_{N(R) H} / \mathrm{MS}_{N(R) T H}$ \\
\hline Tower $\times$ Height $T H_{k l}$ & $\mathrm{MS}_{T H} / \mathrm{MS}_{R T H}$ \\
\hline Round $\times$ Tower $\times$ Height $R T H_{i k l}$ & $\mathrm{MS}_{R T H} / \mathrm{MS}_{N(R) T H}$ \\
\hline $\begin{array}{l}\text { Night(Round) } \times \text { Tower } \times \\
\quad \text { Height } N(R) T H_{j(i) k l}\end{array}$ & No test. Within-subject error \\
\hline
\end{tabular}

flow meter (General Oceanics) secured in the middle of the net opening for the last 2 sampling nights (we did not have water volume estimates for the first night, so raw counts per tow are presented). Samples were transferred into glass jars, preserved in $95 \%$ ethanol and processed as described above. In addition to counts, we also measured each individual (from rostrum to telson) with an ocular micrometer and later calculated the proportion of individuals belonging to different size classes (small juveniles: 1-1.5 $\mathrm{mm}$ in body length; medium juveniles: $1.5-2.5 \mathrm{~mm}$; large juveniles: 2.5 to $4 \mathrm{~mm}$; adults: $>4 \mathrm{~mm}$ ) for each sample. The results for timing of swimming within a tidal cycle were not analyzed statistically and are only presented graphically because there was no within-time replication and a slightly different methodology was used for one night of sampling.

\section{Population trends on muddy shores}

To determine whether amphipods are found on the muddy shores and to assess potential migration patterns, we sampled all along the west coast of Cumberland Basin (Fig. 1B). Mud samples were taken at 9 stations spaced $2 \mathrm{~km}$ apart; sampling started at the northern tip of the Pecks Cove mudflat and ended near the northern section of the Elysian Fields (Fig. 1B). At each site, we collected 5 core samples ( $7 \mathrm{~cm}$ in diameter to the depth of the compacted layer, typically 3 to $7 \mathrm{~cm}$ deep) at random locations along a transect line perpendicular to shore. This was done on 4 occasions at $\sim 3 \mathrm{wk}$ intervals during summer 2009 (early June, early July, late July and mid-August). Samples were filtered through a $250 \mu \mathrm{m}$ mesh sieve (which captures even the smallest Corophium volutator individuals; Crewe et al. 2001) and preserved in $95 \%$ ethanol. Later C. volutator individuals were counted under a dissecting microscope.

Densities of Corophium volutator in the mud were analyzed with a 2-way ANOVA with the fixed factors Station (9 locations) and Time (4 sampling occasions). Densities were squareroot transformed before analysis to meet assumptions of homogeneity of variance and normality of residuals. Multiple comparisons of means for significant fixed effects were conducted with Tukey's test. 


\section{RESULTS}

\section{Vertical distribution of swimmers in the water column}

Corophium volutator individuals were captured at all heights in the water column $(0.3,1,2,3$ and $4 \mathrm{~m}$ above the mudflat substratum) during periods of immersion (Fig. 4). Spatial and temporal variation in density of swimmers (between subject sources of variation) was generally weak, with the exception of patterns specific to towers and sampling round (Round $\times$ Tower interaction, Table 2). There were a few weak but significant interactions between the effect of height and the other factors (Table 2), suggesting there were weak patterns in vertical distribution that were specific to some times and locations. Overall, the effect of height (tested over interactions between random factors) was not significant, thus suggesting a fairly homogenous distribution of swimmers in the water column (Table 2, Fig. 4).

\section{Timing of swimming within a tidal cycle}

The plankton tows conducted at 30 min intervals during entire periods of immersion showed clear patterns that were consistent among the different nights

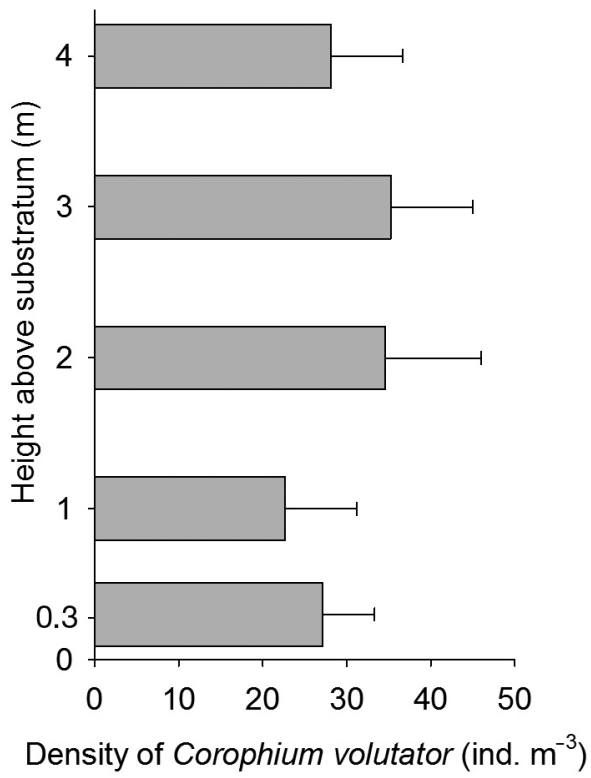

Fig. 4. Corophium volutator. Vertical distribution of swimmers in the water column during periods of immersion occurring at night around the time of new or full moon on the Pecks Cove mudflat in summer 2010. Bars represent mean (+SE) ( $\mathrm{n}=27$ samples) density of swimmers over 9 sampling times with 3 replicate towers
Table 2. Corophium volutator. Results of the mixed-model split-plot ANOVA investigating the spatial and temporal variation in the vertical distribution of swimmers over the Pecks Cove mudflat, Bay of Fundy, in summer 2010. Densities (ind. $\mathrm{m}^{-3}$ ) were $\log _{10}($ datum +1 ) transformed before analysis. Note that some $F$-values are quasi $F$-ratios (Table 1; Underwood 1997)

\begin{tabular}{|lrrcc|}
\hline Source of variation & df & MS & $F$ & $\mathrm{p}$ \\
\hline Round & 2 & 14.35 & 5.25 & 0.08 \\
Night(Round) & 6 & 0.14 & 0.69 & 0.66 \\
Tower & 2 & 0.02 & 0.01 & 0.99 \\
Round $\times$ Tower & 4 & 2.63 & 12.69 & $<0.001$ \\
Between-subject error & 12 & 0.21 & & \\
Height & 4 & 0.61 & 0.87 & 0.57 \\
Round $\times$ Height & 8 & 0.21 & 0.53 & 0.95 \\
Night $($ Round) $\times$ Height & 24 & 0.38 & 2.16 & 0.01 \\
Tower $\times$ Height & 8 & 0.88 & 2.62 & 0.05 \\
Round $\times$ Tower $\times$ Height & 16 & 0.34 & 1.92 & 0.04 \\
Within-subject error & 48 & 0.18 & & \\
\hline
\end{tabular}

of sampling (Fig. 5). For the 3 nights of sampling, there was a strong peak in swimming activity of Corophium volutator during the first hour after initial immersion, followed by a period of little activity for $\sim 1 \mathrm{~h}$ before and after high tide, and a second but much smaller peak just before emersion. Thus, $C$. volutator individuals swam predominantly at flood tide, with a smaller period of activity at ebb tide. After categorizing the swimmers into size classes, patterns became apparent. The flood tide peaks were almost completely dominated by small juveniles $(<1.5 \mathrm{~mm})$ for the 3 nights of sampling (Fig. 6). The less important ebb tide peak was again dominated by small juveniles, but larger proportions of bigger juveniles and adults were more often present than they were at other times in the tidal period, especially for the last 2 sampling nights (Fig. 6). This seasonal change was unrelated to population size structure, as juveniles are proportionally more abundant in the mud in late than in early summer (Peer et al. 1986, Barbeau et al. 2009).

\section{Population trends on muddy shores}

Corophium volutator individuals were found in the mud at all our stations on the muddy shore along the west coast of Cumberland Basin and for all the sampling rounds during summer 2009. For densities, there was a significant interaction between Time and Station $\left(F_{24,142}=2.74, \mathrm{p}<0.0001\right)$, indicating that the spatial distribution across the basin changed through time. In early June 2009, the general trend was a higher density 


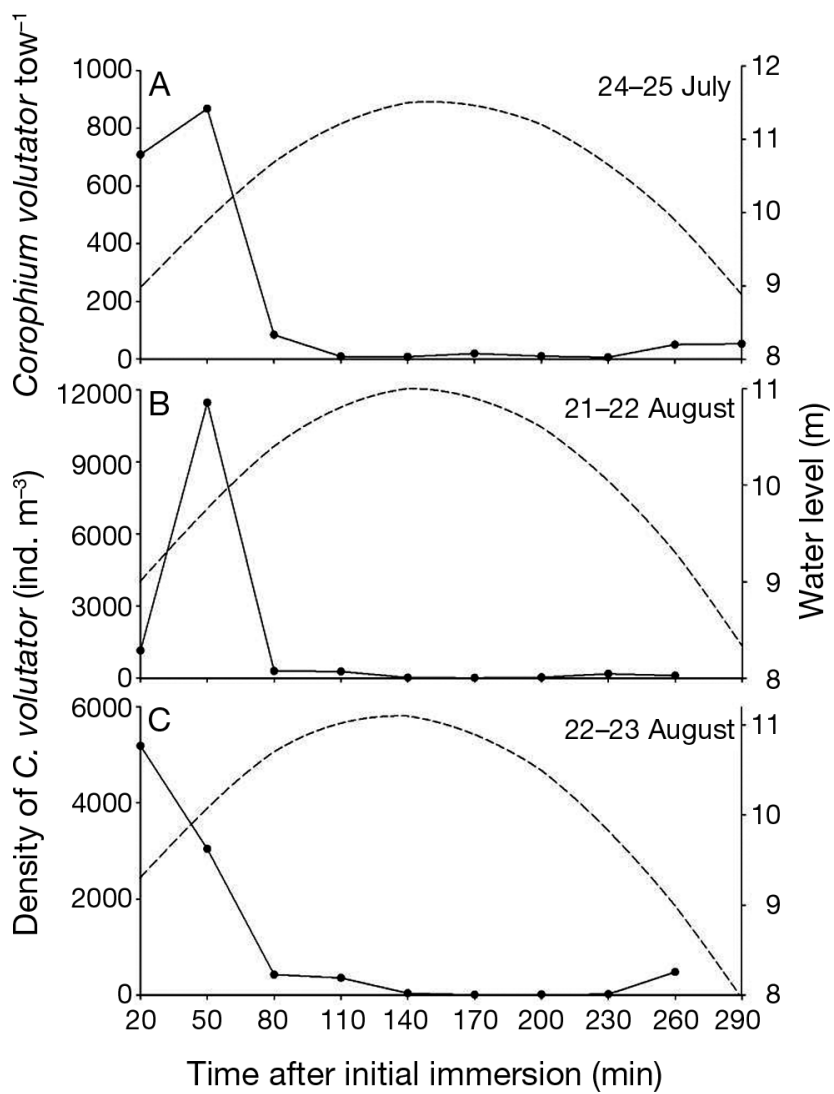

Fig. 5. Corophium volutator. Abundance of swimmers within 3 periods of immersion occurring at night over the Pecks Cove mudflat in 2010. The water column was sampled with a plankton net ( $45 \mathrm{~cm}$ diameter opening) at $30 \mathrm{~min}$ intervals starting just after initial immersion. The solid line represents (A) amphipod abundance per tow or $(B, C)$ amphipod density per volume of water filtered by the tow. The dashed line in all panels represents water level above chart datum (obtained from a tidal prediction model: www.lau.chs-shc.gc. ca/english/Canada.shtml)

at a few stations close to Pecks Cove and a decline farther north (Fig. 7A). In late June, we again observed a gradient in the density of $C$. volutator; the highest density was close to Pecks Cove (Fig. 7B). However, the zone of higher density extended farther than in early June. In mid-July, the distribution pattern was similar to those observed in late June (Fig. 7C). Finally, in midAugust, all differences disappeared and all sites had similar densities (Fig. 7D).

\section{DISCUSSION}

\section{Distances moved by Corophium volutator}

For a Corophium volutator individual to move from one mudflat to the next by using muddy shores in

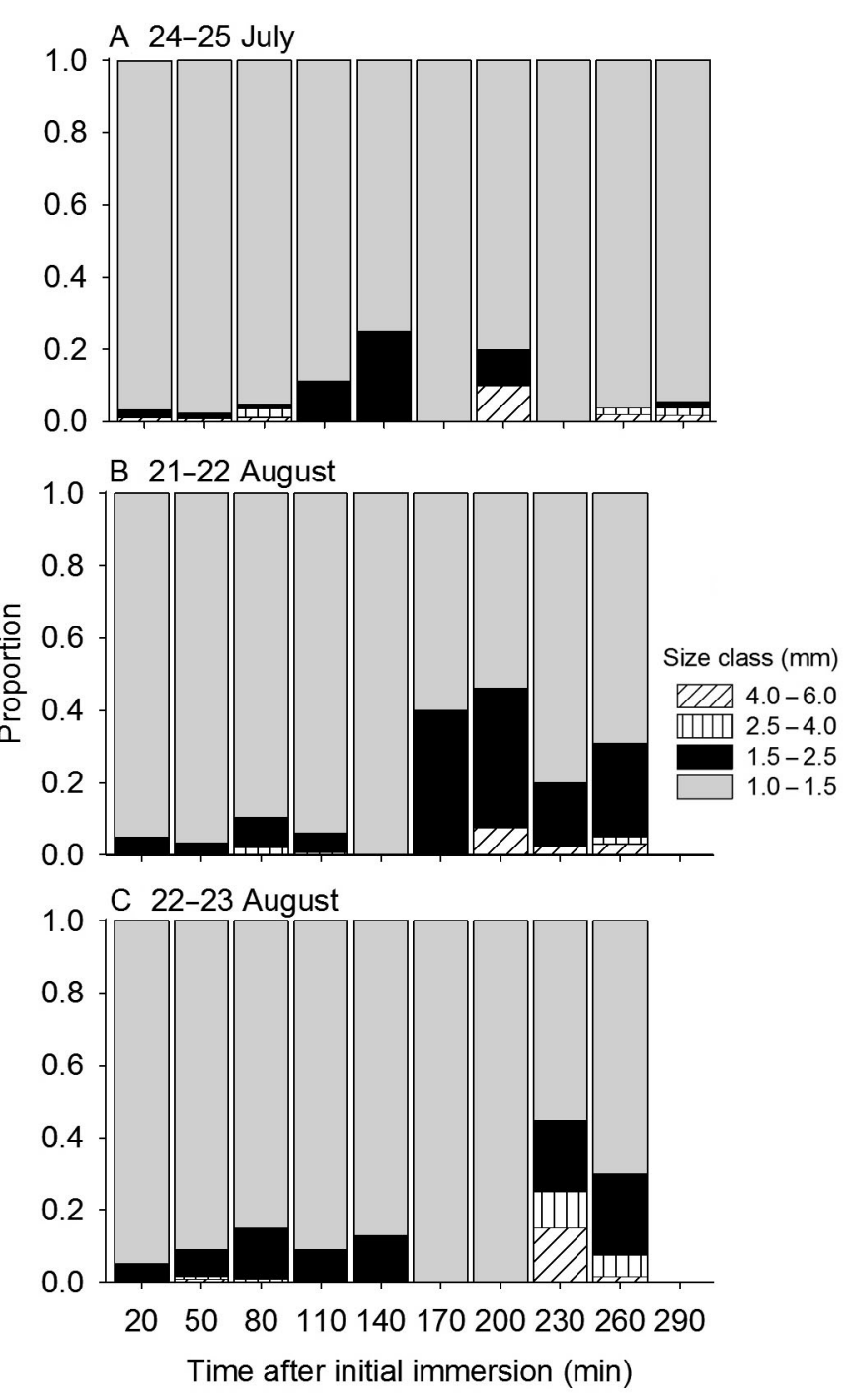

Fig. 6. Corophium volutator. Size distribution of individuals caught swimming in the water column at different times within 3 periods of immersion occurring at night over the Pecks Cove mudflat in 2010. Bars represent proportion of total number of individuals belonging to each size class

Cumberland Basin, it must travel a minimum distance of $\sim 20 \mathrm{~km}$ (Fig. 1B). Because of obvious difficulties with tracking this small species (1 to $10 \mathrm{~mm}$ in body length), we have to rely on indirect methods to determine whether movement on this scale is possible. First, we evaluated the height in the water column at which $C$. volutator can swim. Under the assumption that individuals control their vertical movement (through short bursts of upward swimming, Meadows \& Reid 1966), height of swimming will relate to the length of time they spend in the water, which in turn will relate to the amount of hor- 


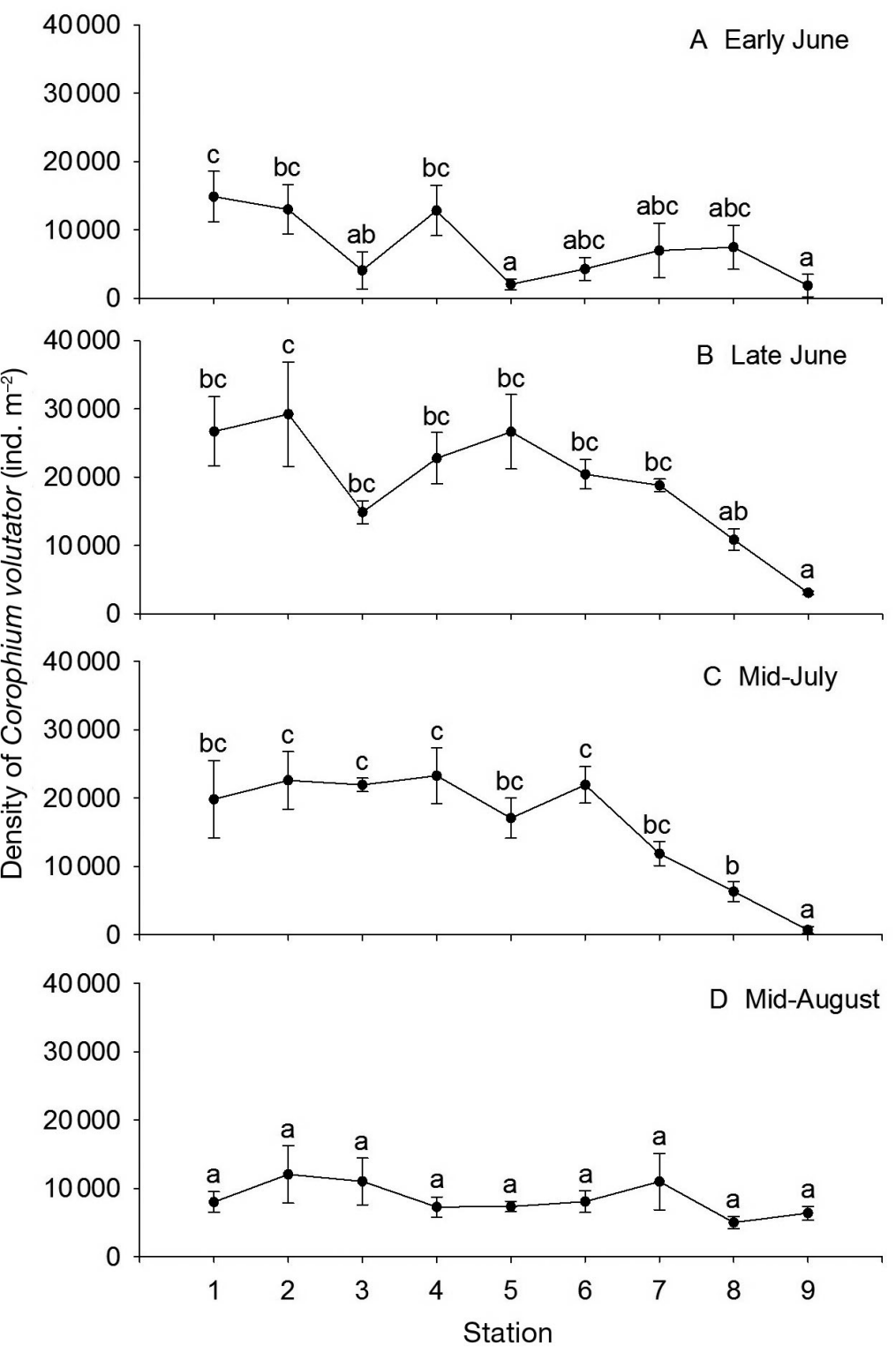

Fig. 7. Corophium volutator. Temporal variation in density (mean $\pm \mathrm{SE}, \mathrm{n}=5$ cores) found in the mud at the different stations along the west coast of Cumberland Basin in 2009 (see Fig. 1 for location of the stations). Stations not sharing a common letter are significantly different (Tukey's post hoc comparisons)

izontal movement. Individuals were caught at all heights with no consistent pattern in vertical distribution; in fact, similar densities of amphipods were observed between $30 \mathrm{~cm}$ and $4 \mathrm{~m}$ above the mudflat substratum (Table 2, Fig. 4). This confirms that C. volutator individuals do not simply hop between locations close to the substratum, but swim high in the water column. Further, the size and sex distribution of swimmers was relatively homogeneous across heights (data presented in Bringloe 2011), which indicated important mixing in the water column had occurred.

Finding high densities of swimmers high above the substratum does not necessarily equate to large-scale movement. Currents are the primary mode of lateral transport (Ford \& Paterson 2001); thus, if amphipods swim mostly at slack tide, they would not move very far. In our study, the highest instantaneous densities of swimmers occurred during the flood tide, a much smaller peak occurred at ebb tide and minimal swimming occurred around slack tide. This confirms that Corophium volutator swims during times of peak water velocity, i.e. at times when there is the greatest potential for lateral movement. Using the information collected, we calculated a minimum horizontal displacement for an amphipod swimming $4 \mathrm{~m}$ above the substrate: assuming a sinking rate of $1.0 \mathrm{~cm} \mathrm{~s}^{-1}$ (Ford \& Paterson 2001 ; i.e. $\sim 7$ min to reach the bottom) and current speeds of 1 to $2 \mathrm{~m} \mathrm{~s}^{-1}$ (Fig. 2), an amphipod would be displaced 400 to $800 \mathrm{~m}$ horizontally. Amphipods probably remain in the water column for longer because of the time required to swim up, and, in a fast turbulent flow, individuals are not likely to sink at their maximal rate. To estimate the maximum theoretical horizontal distance travelled in one swimming event, we used the software WebTide (Dupont et al. 2005) to simulate the path of a particle released near Station 1 at the onset of flood tide; if an individual stays in the water column for the entire flood tide, its net horizontal displacement will be $14.4 \mathrm{~km}$, carrying it from Station 1 to Station 8 (Fig. 8). The actual distance will depend on the time the amphipod spends in the water column and will probably be between the 2 extremes $(0.4$ and $14.4 \mathrm{~km}$ ). Durations of actual swimming bouts should be examined in a future study. Nevertheless, our calculations indicated that $C$. volutator individuals can potentially be carried over the $20 \mathrm{~km}$ of muddy shore between 2 mudflats with only a few discrete movement episodes. 


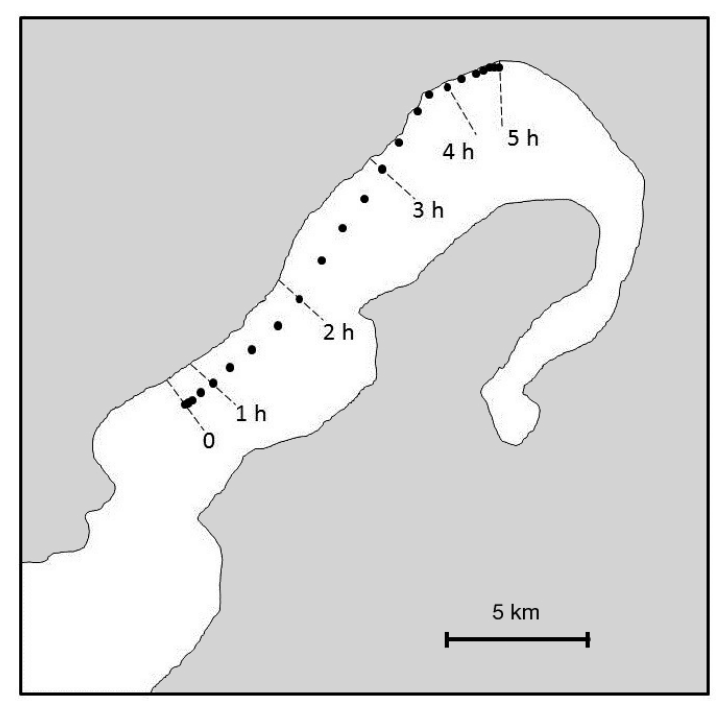

Fig. 8. Movement of a particle released at the northeastern tip of the Pecks Cove mudflat in Cumberland Basin at the start of a flood tide (modelled using WebTide for a spring tide of 13.6 m amplitude; Dupont et al. 2005). Dots represent estimated positions of the particle at $15 \mathrm{~min}$ intervals and dashed lines represent estimated positions at $1 \mathrm{~h}$ intervals

\section{Dispersal along corridors}

If Corophium volutator uses the muddy shores as a corridor for multiple-step migration between mudflats as we hypothesized, we should be able to detect such migration. Because C. volutator swims predominantly during flood tide, we would expect a net transport of amphipods toward the upper part of Cumberland Basin. In fact, the system's behaviour can be approximated by an advection-diffusion model (Turchin 1998). The directed movement of amphipods driven by flood tide swimming corresponds to the advection term, and turbulent mixing during transport coupled with variation in distances travelled by different individuals corresponds to the diffusion term. Under certain conditions, this model can result in travelling waves moving in the direction of advection (Turchin 1998). For our system specifically, this model would predict local increases in amphipod density in the mud that are delayed from station to station as one moves farther in the direction of advection. Eventually, following wave passage, the amphipod densities would even out along the entire muddy shore. Our sampling at different stations along the muddy shores of Cumberland Basin (spanning $\sim 20 \mathrm{~km}$ ) showed amphipod behaviour consistent with these predictions (Fig. 7). For our first sampling round, we only had high densities at the stations upstream (from the direction of advection).
During summer (late June and mid-July sampling rounds), the stations farther downstream gradually filled up. Near the end of the summer (mid-August), all stations had comparable densities of amphipods (Fig. 7). Overall, the muddy shores showed population trends that were qualitatively consistent with the predictions of a theoretical model and suggest that a 'wave' of individuals leaves Pecks Cove and moves along the muddy shores, eventually approaching the Elysian Fields.

Interestingly, some amphipods also swam during ebb tide, although overall densities were much lower than during flood tide. This second peak in swimming activity had a higher proportion of large individuals compared with the flood tide peak (the latter was almost entirely composed of small juveniles). In the laboratory, Coffin (2011) also observed ebb tide swimming in Corophium volutator larger than $3 \mathrm{~mm}$. This suggests there is a migration pattern within the life of some individuals; specifically, individuals move up the basin, grow and eventually come back down the basin. During this ebb tide swimming, some individuals near the tip of the basin (Station 9 and farther up) are likely to drift to the eastern coast of Cumberland Basin and thus end up on a different mudflat. Overall, C. volutator exhibits selective tidalstream transport, a common method used by marine fish and invertebrates to move up and down an estuary (Gibson 2003).

Observations and preliminary measurements of current patterns suggest the presence of a large, counter clockwise eddy over the Pecks Cove mudflat (and possibly other mudflats located in bays and coves) during the entire immersion period. This eddy results in consistent directional movement of amphipods (Drolet \& Barbeau 2011) and probably keeps most swimmers from leaving the bay or cove. However, the direction of amphipod movement is not as consistent far from shore, near the northern part of the mudflat (Drolet \& Barbeau 2011); this area could be the edge of the eddy. As well, densities of Corophium volutator in the mud are the lowest in that general area (northeastern) part of the mudflat. This suggests that this area is the origin of the migration where individuals leave the mudflat to disperse along the coast.

\section{Metapopulation dynamics}

The interplay between the spatial arrangements of habitat, movement behaviour of a species and hydrodynamic patterns has been a central theme in the 
recent study of marine populations (Underwood \& Keough 2001). The degree of connectivity between patches of habitat of different size ultimately determines the type of dynamics, going from isolated populations solely driven by local demography to large areas well mixed and synchronized by a common pelagic larval pool. Between these 2 extremes lies the possibility of metapopulation dynamics. For this vast theory, which was developed for highly fragmented terrestrial landscapes, to be useful for marine systems, 4 conditions must be met (Hanski 1997). (1) Discrete patches of suitable habitat are present and can sustain local breeding populations. (2) Local population dynamics are asynchronous to a certain extent in the different populations. (3) Local populations are at risk of becoming extinct. (4) Local populations are connected by dispersal.

For the first condition, most marine populations are aggregated at some spatial scale, although the causes are not always related to spatial arrangement of suitable habitat (Sale et al. 2006). Also, it is not always clear whether aggregations of individuals represent local breeding populations, given the extent of pelagic larval dispersal (e.g. Barnay et al. 2003). In our system, suitable habitat for Corophium volutator (intertidal mud) is clearly organized in discrete patches, i.e. large intertidal mudflats. Also, extensive self-recruitment in this species with direct development, coupled with intense within-mudflat redistribution of individuals, results in synchronous local population dynamics across a mudflat (Drolet \& Barbeau in press).

Many marine systems do not meet the second condition of asynchronous dynamics among different local populations. This is because the size of the habitat patches is often small compared with the scale of dispersal of planktonic larvae (Pfister 1998). In our system, local dynamics of Corophium volutator differ between mudflats that are close together (Barbeau et al. 2009), suggesting that connectivity is not substantial enough to synchronize dynamics (Ranta et al. 1995).

The usefulness of the third condition, stating that all or some populations are at risk of becoming extinct, has been debated for marine systems (Smedbol et al. 2002, Kritzer \& Sale 2004). Populations of marine animals are generally quite large and not prone to extinction. Nevertheless, severe population crashes of Corophium volutator have been documented in Europe (Jensen \& Mouritsen 1992) and observed in the Bay of Fundy (see references in Introduction). Within the last $10 \mathrm{yr}$, we were unable to find $C$. volutator at certain times at 3 mudflats that previously had abundant populations. We cannot say that these events were local extinctions as we could obviously not search the entire area (some mudflats are over 1000 ha in area), but they demonstrate important fluctuations, typical of populations prone to extinction.

The fourth condition, connectivity between populations, is the main scope of this paper. In addition to the tidal current-driven dispersal along muddy shores reported in this paper, mudflats might also exchange individuals (of different species of invertebrates) through ice rafting during the winter months (Macfarlane et al. 2011). In support of the field results, preliminary population genetic data suggest there are low levels of differentiation between mudflats that are close together (T. Einfeldt unpubl. data). As well, after the crashes described above, populations of Corophium volutator recovered after a few years. Finally, newly formed mudflats (through the building of causeways) were rapidly colonized by C. volutator (Partridge 2000). All these points suggest that $C$. volutator has the potential to physically move from mudflat to mudflat and establish a population in an empty patch.

Overall, our system seems to meet all the conditions necessary for a metapopulation approach to be both appropriate and informative. To date, the number of marine systems known to meet all the above conditions is low (see Dybdahl 1994, Johnson 2006, Reed et al. 2006), but is likely to increase with future studies. In an effort to make metapopulation theory more broadly applicable to marine systems, some particularities will need to be taken into account to adjust the theory, because it was originally developed for terrestrial systems (Kritzer \& Sale 2006). Specifically, the spatial arrangement of habitat patches and the high dependence of dispersal of organisms on hydrodynamic conditions must be considered.

Here, we considered these issues and refined the concept for our system and potentially other softsediment coastal systems. A useful model could include a relatively small number of local populations (2 to 5 large intertidal mudflats) connected by corridors (muddy shores) that could facilitate the dispersal of individuals. The behaviour of such a system of populations will be highly dependent upon the specific spatial arrangement of the flats and corridors, details of hydrodynamic conditions and behaviour of individuals. Unidirectional dispersal is likely, given the tendency of individuals to swim at particular times within a tidal cycle (Gibson 2003). A local population of Corophium volutator could be affected 
by the sudden arrival of a small number of individuals (relative to the total population found at a mudflat) when a travelling wave reaches it; this could potentially lead to source-sink dynamics if the local population at the receiving end is not self-supporting (Pulliam 1988). Given the relatively small number of local populations and the unidirectional dispersal in our modelled system, regional persistence time (i.e. at the level of a basin or bay, as opposed to the level of a mudflat) is not likely to be much increased by adding connectivity between individual mudflats. However, parameterization of such a spatially structured population model could be very informative in terms of time to recovery and probability of recolonization after local extinctions (i.e. at the level of mudflats).

We focussed our work in Cumberland Basin, but similar spatial arrangements of mudflats and muddy shores are observed in the other upper branches of the Bay of Fundy (Shepody Bay, Minas Basin and Cobequid Bay; see Hicklin \& Smith 1984 and Peer et al. 1986 for maps). We believe similar dynamics might operate within each branch, but connectivity between branches may be unlikely. Detailed information about the within-mudflat dynamics throughout the Bay of Fundy is currently being gathered to identify potential source and sink Corophium volutator populations. As well, population genetics work is underway to evaluate patterns of connectivity. Overall, the spatially structured population model we conceptually present here could be applicable to softsediment coastal systems throughout the world for species with either postsettlement dispersive strategies (assuming a high level of self-recruitment) or direct development. Future research should focus on large-scale movement of infauna and its consequences. The spatial arrangement of populations we described has important conservation implications. Common development practices (e.g. construction of dykes and causeways, development close to shoreline) can disrupt the continuous corridors, which could impede normal dispersal. These practices may need to be minimized or reconsidered as they could disconnect a sink from its source population, increase the odds of local population extinction or decrease the odds of colonization after a local extinction.

Acknowledgements. We are grateful to C. Macfarlane, A. Mayberry and A. Savoie for their help in the field, C. Sheehy for the photograph of the tower, S. Haigh and D. Greenberg for information on tidal currents in the upper Bay of Fundy, J.-S. Lauzon-Guay and 3 anonymous reviewers for insightful comments on the manuscript and the mudflat ecology group at University of New Brunswick, Mount Alli- son University and Carleton University for useful discussions. This project was funded by a Strategic Project Grant from the Natural Science and Engineering Research Council of Canada (NSERC), a Research Tools and Instruments grant (NSERC) and the Canada Summer Jobs program.

\section{LITERATURE CITED}

Armonies W (1996) Changes in distribution patterns of 0group bivalves in the Wadden Sea: byssus-drifting releases juveniles from the constraints of hydrography. J Sea Res 35:323-334

Armonies W, Hartke D (1995) Floating of mud snails Hydrobia ulvae in tidal waters of the Wadden Sea, and its implications in distribution patterns. Helgol Meeresunters 49:529-538

Barbeau MA, Grecian LA, Arnold EE, Sheahan DC, Hamilton DJ (2009) Spatial and temporal variation in the population dynamics of the intertidal amphipod Corophium volutator in the upper Bay of Fundy, Canada. J Crustac Biol 29:491-506

Barnay AS, Ellien C, Gentil F, Thiebaut E (2003) A model study on variations in larval supply: Are populations of the polychaete Owenia fusiformis in the English Channel open or closed? Helgol Mar Res 56:229-237

Bringloe TT (2011) A large scale and detailed study of swimming Corophium volutator throughout the upper Bay of Fundy, including vertical distribution and timing of swimming. BSc thesis, University of New Brunswick, Fredericton

Coffin MRS (2011) Complex interactions between the mud snail Ilyanassa obsoleta and the amphipod Corophium volutator on intertidal mudflats. MSc thesis, University of New Brunswick, Fredericton

Coulthard ME, Hamilton DJ (2011) Effects of Ilyanassa obsoleta (Say) on the abundance and vertical distribution of Corophium volutator (Pallas) on mudflats of the upper Bay of Fundy. J Exp Mar Biol Ecol 397:161-172

> Crewe TL, Hamilton DJ, Diamond AW (2001) Effects of mesh size on sieved samples of Corophium volutator. Estuar Coast Shelf Sci 53:151-154

> Cummings VJ, Pridmore RD, Thrush SF, Hewitt JE (1995) Post settlement movement by intertidal benthic macroinvertebrates: Do common New Zealand species drift in the water column? NZ J Mar Freshw Res 29:59-67

Desplanque C, Mossman DJ (2004) Tides and their seminal impact on the geology, geography, history, and socioeconomics of the Bay of Fundy, eastern Canada. Atl Geol 40:1-130

Drolet D (2009) Distribution and movement of the intertidal amphipod Corophium volutator in the upper Bay of Fundy. PhD thesis, University of New Brunswick, Fredericton

> Drolet D, Barbeau MA (2009) Diel and semi-lunar cycle in the swimming activity of the intertidal, benthic amphipod Corophium volutator in the upper Bay of Fundy, Canada. J Crustac Biol 29:51-56

Drolet D, Barbeau MA (2011) Movement patterns drive within-mudflat distribution of an intertidal amphipod. Mar Ecol Prog Ser 431:255-265

Drolet D, Barbeau MA (in press) Population structure of resident, immigrant and swimming Corophium volutator (Amphipoda) on an intertidal mudflat in the Bay of Fundy, Canada. J Sea Res 
Dupont F, Hannah CG, Greenberg D (2005) Modelling the sea level of the upper Bay of Fundy. Atmos-Ocean 43: 33-47

Dybdahl MF (1994) Extinction, recolonization, and the genetic structure of tidepool copepod populations. Evol Ecol 8:113-124

Emerson CW, Grant J (1991) The control of soft-shell clam (Mya arenaria) recruitment on intertidal sandflats by bedload sediment transport. Limnol Oceanogr 36:1288-1300

> Essink K, Kleef HL, Visser W (1989) On the pelagic occurrence and dispersal of the benthic amphipod Corophium volutator. J Mar Biol Assoc UK 69:11-15

Ford RB, Paterson DM (2001) Behaviour of Corophium volutator in still versus flowing water. Estuar Coast Shelf Sci 52:357-362

Gibson RN (2003) Go with the flow: tidal migration in marine animals. Hydrobiologia 503:153-161

> Gilmurray MC, Daborn GR (1981) Feeding relations of the Atlantic silverside Menidia menidia in the Minas Basin, Bay of Fundy. Mar Ecol Prog Ser 6:231-235

Grimm V, Reise K, Strasser M (2003) Marine metapopulations: a useful concept? Helgol Mar Res 56:222-228

> Haddad NM, Bowne DR, Cunningham A, Danielson BJ, Levey DJ, Sargent S, Spira T (2003) Corridor use by diverse taxa. Ecology 84:609-615

> Hamilton DJ, Diamond AW, Wells PG (2006) Shorebirds, snails, and the amphipod (Corophium volutator) in the upper Bay of Fundy: top-down vs. bottom-up factors, and the influence of compensatory interactions on mudflat ecology. Hydrobiologia 567:285-306

Hanski I (1997) Metapopulation dynamics: from concepts and observations to predictive models. In: Hanski I, Gilpin ME (eds) Metapopulation biology, ecology, genetics, and evolution. Academic Press, San Diego, CA, p 69-91

Hanski I (1998) Metapopulation dynamics. Nature 396: 41-49

Hanski I (2001) Population dynamics consequences of dispersal in local populations and in metapopulations. In: Clobert J, Danchin E, Dhondt AA, Nichols JD (eds) Dispersal. Oxford University Press, Oxford, p 283-298

> Hanski I, Ovaskainen O (2003) Metapopulation theory for fragmented landscapes. Theor Popul Biol 64:119-127

> Hicklin PW, Smith PC (1984) Selection of foraging sites and invertebrate prey by migrant semipalmated sandpipers, Calidris pusilla (Pallas), in Minas Basin, Bay of Fundy. Can J Zool 62:2201-2210

- Hughes RG (1988) Dispersal by benthic invertebrates: the in situ swimming behaviour of the amphipod Corophium volutator. J Mar Biol Assoc UK 68:565-579

> Jennings LB, Hunt HL (2009) Distances of dispersal of juveniles bivalves (Mya arenaria (Linnaeus), Mercenaria mercenaria (Linnaeus), Gemma gemma (Totten)). J Exp Mar Biol Ecol 376:76-84

Jensen KT, Mouritsen KN (1992) Mass mortality in two common soft-bottom invertebrates, Hydrobia ulvae and Corophium volutator-the possible role of trematodes. Helgol Meeresunters 46:329-339

Johnson MP (2006) Rocky intertidal invertebrates: the potential for metapopulation within and among shores. In: Kritzer JP, Sale PF (eds) Marine metapopulations. Academic Press, San Diego, CA, p 247-270

- Junkins R, Kelaher B, Levinton J (2006) Contributions of adult oligochaete emigration and immigration in a dynamic soft-sediment community. J Exp Mar Biol Ecol 330:208-220
Komatsu T, Kawai H (1992) Measurements of time-averaged intensity of water motion with plaster balls. J Oceanogr 48:353-365

Kritzer JP, Sale PF (2004) Metapopulations in the sea: from Levins' model to marine ecology and fisheries science. Fish Fish 5:131-140

Kritzer JP, Sale PF (2006) The future of metapopulation science in marine ecology. In: Kritzer JP, Sale PF (eds) Marine metapopulations. Academic Press, San Diego, CA

MacDonald EC, Ginn MG, Hamilton DJ (2012) Variability in foraging behaviour and implications for diet breadth among semipalmated sandpipers staging in the upper Bay of Fundy. Condor 114:135-144

Macfarlane CB, Drolet D, Barbeau MA, Hamilton DJ, Ollerhead J (2011) Movement of drift ice as a vector for transport of sediment and invertebrates on intertidal mudflats of the Bay of Fundy. In: Proceedings of the 16th workshop on the hydraulics of ice covered rivers, Winnipeg, Manitoba. Committee on River Ice Processes and the Environment, p 238-248

McCurdy DG, Forbes MR, Logan SP, Lancaster D, Mautner SI (2005) Foraging and impacts by benthic fish on the intertidal amphipod Corophium volutator. J Crustac Biol 25:558-564

> Meadows PS, Reid A (1966) The behaviour of Corophium volutator (Crustacea: Amphipoda). J Zool 150:387-399

> Mouritsen KN, Mouritsen LT, Jensen KT (1998) Change of topography and sediment characteristics on an intertidal mud-flat following mass-mortality of the amphipod Corophium volutator. J Mar Biol Assoc UK 78:1167-1180

Partridge VA (2000) Aspects of the winter ecology and spring recolonization of the Windsor mudflat. MSc thesis, Acadia University, Wolfville

> Peer DL, Linkletter LE, Hicklin PW (1986) Life history and reproductive biology of Corophium volutator (Crustacea: Amphipoda) and the influence of shorebird predation on population structure in Chignecto Bay, Bay of Fundy, Canada. Neth J Sea Res 20:359-373

Pfister CA (1998) Extinction, colonization, and species occupancy in tidepool fishes. Oecologia 114:118-126

> Pridmore RD, Thrush SF, Hewitt JE, Roper DS (1990) Macrobenthic community composition of six intertidal sandflats in Manukau Harbour, New Zealand. NZ J Mar Freshw Res 24:81-96

> Pulliam HR (1988) Sources, sinks, and population regulation. Am Nat 132:652-661

Quinn GP, Keough MJ (2002) Experimental design and data analysis for biologists. Cambridge University Press, Cambridge

> Ranta E, Kaitala V, Lindstrom J, Linden H (1995) Synchrony in population dynamics. Proc R Soc Lond B Biol Sci 262: 113-118

Reed DC, Kinlan BP, Raimondi PT, Washburn L, Gaylord B, Drake PT (2006) A metapopulation perspective on the patch dynamics of giant kelp in southern California. In: Kritzer JP, Sale PF (eds) Marine metapopulations. Academic Press, San Diego, CA, p 353-386

Sale PF, Hanski I, Kritzer JP (2006) The merging of metapopulation theory and marine ecology: establishing the historical context. In: Kritzer JP, Sale PF (eds) Marine metapopulations. Academic Press, San Diego, CA, p 3-28

Shepherd PCF, Partridge VA, Hicklin PW (1995) Changes in sediment types and invertebrate fauna in the intertidal mudflats of the Bay of Fundy between 1977 and 1994. 
Can Wildl Serv Tech Rep 237. Canadian Wildlife Service, Environment Canada, Ottawa

Smedbol RK, McPherson A, Hansen MM, Kenchington E (2002) Myths and moderation in marine 'metapopulations'? Fish Fish 3:20-35

Sprague AJ, Hamilton DJ, Diamond AW (2008) Site safety and food affect movements of semipalmated sandipipers (Calidris pusilla) migrating through the upper Bay of Fundy. Avian Conserv Ecol 3(2):4 www.ace-eco.org/ vol3/iss2/art4/

Thrush SF, Pridmore RD, Hewitt JE, Cummings VJ (1991) Impact of ray feeding disturbances on sandflat macrobenthos: Do communities dominated by polychaetes

Editorial responsibility: Jana Davis, Annapolis, Maryland, USA and shellfish respond differently? Mar Ecol Prog Ser 69: 245-252

Turchin P (1998) Quantitative analysis of movement: measuring and modeling population redistribution in plants and animals. Sinauer Associates, Sunderland, MA

Underwood AJ (1997) Experiments in ecology: their logical design and interpretation using analysis of variance. Cambridge University Press, Cambridge

Underwood AJ, Keough MJ (2001) Supply-side ecologythe nature and consequences of variations in recruitment of intertidal organisms. In: Bertness MD, Gaines SD, Hay ME (eds) Marine community ecology. Sinauer Associates, Sunderland, MA, p 183-200

Submitted: August 8, 2011; Accepted: November 10, 2011

Proofs received from author(s): February 17, 2012 